\title{
Recent Advances in Platelet Transcriptomics
}

\author{
Dmitri V. Gnatenko ${ }^{a}$ Wadie F. Bahou ${ }^{a, b}$ \\ a Department of Medicine,

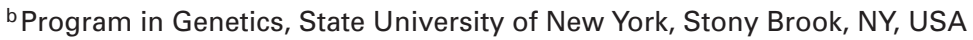

\section{Key Words}

Platelets - mRNA profiling - Transcriptome .

Platelet mRNA . Platelet disorders

\section{Summary}

Platelets are anucleated cells that contain small amounts of mRNA of megakaryocyte origin and possess the capacity for signal-dependent pre-mRNA splicing. They have an important role in diverse hemostatic and pathological disorders, including vascular remodeling, inflammation and wound repair. Recent progress in highthroughput mRNA profiling techniques permitted first insights into the platelet transcriptome - a catalogue of all mRNA transcripts expressed in platelets. It is evident that platelets have a unique and reproducible molecular signature. Detailed analysis of the platelet transcriptome has resulted in the identification of many genes and proteins, previously unknown to be expressed in platelets. Furthermore, microarray analysis was applied to platelet disorders: i) as potentially a powerful tool for differential diagnosis, ii) to study the molecular basis of the disease and iii) to identify potential targets for therapy. In this review, we focus on recent applications of transcript profiling to platelet studies. We briefly review current approaches to transcriptome analysis and describe practical application of these approaches to investigate molecular mechanisms of essential thrombocythemia, gray platelet syndrome and polycythemia vera.

\author{
Schlüsselwörter \\ Thrombozyten · mRNA-Profiling · Transkriptom • \\ Thrombozyten-mRNA . Thrombozytenerkrankungen
}

\section{Zusammenfassung}

Thrombozyten sind Zellfragmente ohne Zellkern, die eine geringe Menge mRNA megakaryozytären Ursprungs enthalten und über die Fähigkeit zu signalabhängigem premRNA-Splicing verfügen. Sie spielen eine wichtige Rolle in verschiedenen hämostatischen und pathologischen Erkrankungen, einschließlich vaskulären Veränderungen, Entzündungen und Wundheilung. Jüngste methodische Fortschritte des umfassenden mRNA-Profilings ermöglichten ersten Einsichten in das Thrombozyten-Transkriptom - einer Auflistung aller in Thrombozyten vorkommender mRNA-Transkripte. Es wurde eindeutig gezeigt, dass Thrombozyten eine einzigartige und reproduzierbare molekulare Signatur aufweisen. Eine detaillierte Analyse des Thrombozyten-Transkriptoms führte zur Identifizierung vieler Gene und Proteine, von denen bisher nicht bekannt war, dass sie in Thrombozyten auftreten. Des Weiteren wurde die Mikroarray-Analyse auf Thrombozytenerkrankungen angewendet: 1) als mögliches wichtiges Instrument zur Differenzialdiagnose, 2) zur Untersuchung der molekularen Grundlage der Erkrankung und 3) zur Identifizierung möglicher Ziele im Rahmen einer Therapie. In diesem Artikel konzentrieren wir uns auf neueste Anwendungen des Transkript-Profiling zur Untersuchung von Thrombozyten. Wir gehen auf neue Ansätze in der Transkriptom-Analyse ein und beschreiben den praktischen Einsatz dieser Methoden bei der Untersuchung molekularer Mechanismen der essentiellen Thrombozythämie, des Gray-Platelet-Sydroms und der Polyzythämie vera.

\begin{tabular}{ll}
\hline KARGER & @ 2006 S. Karger GmbH, Freiburg \\
Fax +497614520714 & Accessible online at: \\
$\begin{array}{l}\text { E-mail Information@Karger.de } \\
\text { www.karger.com }\end{array}$ & www.karger.com/tmh
\end{tabular}




\section{Introduction}

Platelets play critical roles in normal hemostatic processes and pathologic conditions, such as thrombosis, vascular remodeling, inflammation and wound repair. Generated as cytoplasmic buds from precursor bone marrow megakaryocytes, platelets are anucleate and lack nuclear DNA although retaining small amounts of megakaryocyte-derived mRNAs [1, 2]. Platelets on average contain as little as $2 \times 10^{-3} \mathrm{fg}$ mRNA/cell (approximately 3-4 logs less RNA than a typical nucleated cell [3]), although younger platelets contain relatively larger amounts of mRNA, as determined by use of fluorescent nucleic acid dyes such as thiazole orange [4]. Platelets contain rough endoplasmic reticulum and polyribosomes and retain the ability for protein biosynthesis from cytoplasmic mRNA [5, 6]. Quiescent platelets generally display minimal translational activity, although newly formed platelets synthesize various $\alpha$-granule and membrane glycoproteins, including GPIb and GPIIb/IIIa $\left(\alpha_{\mathrm{IIb}} \beta_{3}\right)$. Furthermore, stimulation of quiescent platelets by agonists, such as $\alpha$-thrombin, increases protein synthesis of various platelet proteins, including Bcl-3 [7].

Some diseases originating from either inherited (both quantitative and qualitative) or acquired platelet disorders are characterized by the deficiency of key platelet-specific proteins [8, 9]. Better understanding of the molecular mechanisms of platelet pathology requires detailed studies of the entire pool of platelet mRNA transcripts and proteins. Until recently, low levels of mRNA in platelets made mRNA profiling analysis challenging. But advances in gene profiling technologies, coupled with the completion of the Human Genome Project, have permitted first insights into the platelet transcriptome - the catalogue of the entire population of mRNAs transcripts present in platelets. Historically, the platelet mRNA content was considered invariant, gradually declining with cell senescence, presumably at various rates for distinct transcripts. The traditional paradigm was re-configured with the discovery of signal-dependent pre-mRNA splicing in platelets [10]. This observation established that platelets possess essential spliceosome components, such as U1 70K protein and all U snRNAs, as well as select unspliced pre-mRNAs from megakaryocytes. Interestingly, these spliceosomes retain the unique ability of pre-mRNA splicing in the cytoplasm (as opposed to the typical nuclear location) - a functional capacity undescribed in any other type of mammalian cells. Specifically, platelets precisely excise introns from interleukin- $1 \beta$ pre-mRNA in response to surface receptor activation. Signal-dependent splicing allows platelets to alter the pool of translatable messages from the same invariable pool of transcripts in response to cellular activation/stimulation. This discovery emphasizes the importance of accurate platelet transcript profiling - along with studies focusing on the correlation between mRNA abundance and protein expression - in order to optimally dissect complex processes of platelet function.

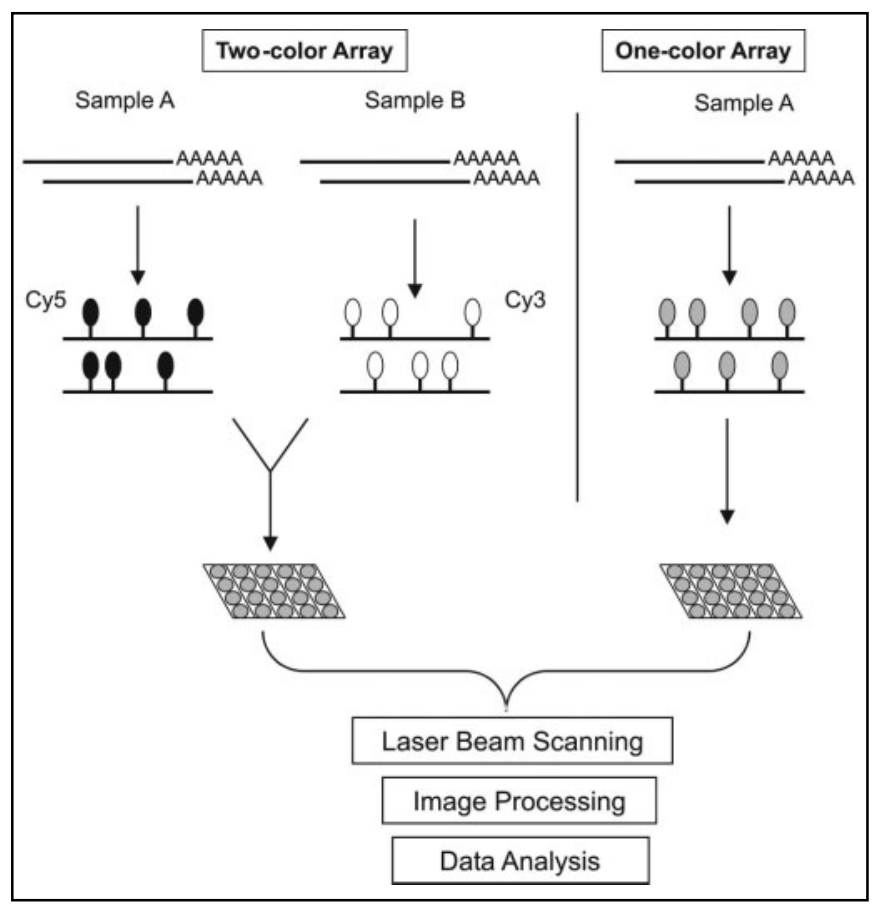

Fig. 1. Schema of microarray mRNA analyses. Two-color microarray analysis provides information on the differential expression of genes between two tissue samples. One-color microarray analysis measures gene expression profile from a single tissue and have enough built-in controls and standards to normalize data so that different arrays can be analyzed simultaneously. Both analyses include transcript labeling (either cDNA or cRNA), hybridization to the chip, washing, scanning and data processing.

Two complimentary techniques are predominantly used for mRNA transcript profiling - microarray and serial analysis of gene expression (SAGE). Microarray technology represents a 'closed' profiling strategy limited by the target genes imprinted onto gene chips. In contrast, SAGE is an 'open' architectural system that can be used to identify novel genes and to quantify differentially expressed mRNAs [11,12]. Taken together, these techniques provide a panoramic definition of the entire pool of mRNA transcripts, constituting the transcriptome. In this review, we focus on the application of recent platelet transcriptome findings to the general understanding of molecular mechanisms of platelet function and provide perspectives of molecular diagnostics of platelet-associated diseases.

\section{Approaches to Transcriptome Analysis (mRNA Profiling)}

\section{Microarray Analysis}

Microarray analysis adapts artificially constructed grids of known DNA samples such that each element of the grid probes for a specific RNA sequence. These are then used to capture and quantify RNA transcripts [13]. Many different 
protocols and types of microarray have been developed to date - oligonucleotide and cDNA arrays, commercially available whole-genome arrays and custom-made tissue-specific arrays. All of them require i) isolation of RNA from biological sample, ii) copying of RNA into either cRNA or cDNA, simultaneously incorporating either fluorescent nucleotides or a tag that is later used for fluorescent labeling, iii) hybridization to a microchip containing a grid of DNA probes, iv) washing, v) labeling (if necessary, depending on the protocol), vi) scanning under laser light, and vii) image processing, data extraction and analysis (fig. 1).

Both cDNA and oligonucleotide arrays are used in microarray experiments, either purchased commercially or generated for tissue-specific analyses. Irrespective of the approach, bioinformatic clustering tools are required for delineation of closely related expression patterns that might be controlled by common regulatory mechanisms. Oligonucleotide microarrays provide for an absolute signal intensity for a single sample at a specific point in time, whereas spotted cDNA microarrays provide comparative signal intensities between two simultaneously processed tissue sources. The sources for cDNA arrays are generally PCR products from expressed sequence tags (ESTs) or from cell (tissue)-specific sources, followed by robotic fabrication onto glass slides ('spotted cDNA microarray'). In contrast, the technology for oligonucleotide arrays has been pioneered commercially using a combination of photolithography and solid-phase DNA synthesis. The latter technology generates relatively short (25-mer) oligonucleotides specific for transcripts of interest, with sequence-specific mismatches (1-base pair/oligonucleotide) that serve as important internal controls to assess hybridization specificity and 'system noise'. In addition, concomitant use of multiple oligonucleotide primers encompassing different regions of the same transcript allow for more accurate and reliable profiling. Software algorithms compare the relative intensities of each transcript-specific signal, quantifying integrated signal specificities (perfect match) adjusted for non-specific hybridization (mismatch) to the transcript control. These average difference values, typically reported in logarithmic (base 2) transformations, generally reflect relative transcript abundance. Oligonucleotide arrays have been used to distinguish acute myelogenous leukemia from acute lymphoblastic leukemia, suggesting that transcript signatures may provide for novel, discriminatory methods for molecular classification [14].

In contrast, spotted cDNA arrays typically can be adapted for delineation of relative transcript abundance between two cellular sources (i.e. control and transformed cells). In this case, one mRNA population is labeled with one fluorophore (i.e. $\mathrm{Cy} 3)$ and the other with a wavelength-restricted alternative fluorophore (i.e. Cy5), and both pools are competitively cohybridized to the same slide for quantification of relative expression of individual transcripts. The utility of such an approach has demonstrated distinct mRNA profiles in patients with diffuse large B-cell lymphoma. Hierarchical clustering
Fig. 2. Schema of SAGE as an approach to mRNA transcript profiling. $\mathrm{AE}=$ anchoring enzyme, $\mathrm{TE}=$ tagging enzyme.

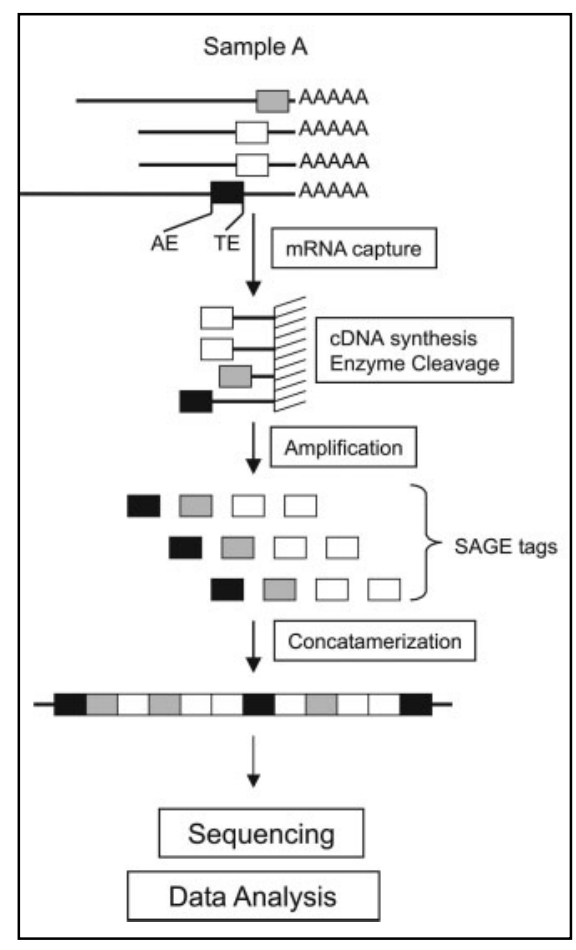

tools were used to sub-classify these lymphomas and to correlate gene expression patterns with disease outcome [15]. Similarly, gene expression profiling appeared to predict the outcome of young patients with breast cancer [16], suggesting that molecular classification may become a more broadly utilized technology for rational therapy of certain human diseases. Several different microarray systems are commercially available, including whole-genome microarrays from Affymetrix (Santa Clara, CA, USA), Applied Biosystems (Forster City, CA, USA), MWG-Biotech AG (Ebersberg, Germany) and others.

\section{Serial Analysis of Gene Expression}

Classical SAGE [11] relies on the observation that short $(<10$ bp) sequences within 3'-mRNAs can stringently discriminate among the approximately 30,000 genes comprising the human genome, assuming a random nucleotide distribution along a 9-bp stretch $\left(4^{9} \mathrm{bp}=262,244\right.$ random nucleotide combinations). SAGE is completed by i) isolation of RNA from biological sample, ii) preparation of a 3' end-specific cDNA library, iii) generation and concatenation of tags from the cDNA library using an anchoring enzyme, such as NlaIII, and a tagging enzyme, such as BsmFI, and iv) cloning of tag concatemers into a sequencing vector and performing automated sequencing (fig. 2). The sequence of each tag along with its positional location, uniquely identifies the gene from which it is derived, and differentially expressed genes can be identified in a quantitative manner since the frequency of tag detection 
Table 1. Megakaryocyte and platelet microarray studies

\begin{tabular}{|c|c|c|c|c|c|c|}
\hline & $\begin{array}{l}\text { Gnatenko et al., } \\
2003 \text { [22] }\end{array}$ & $\begin{array}{l}\text { Gnatenko et al., } \\
2005 \text { [45] }\end{array}$ & $\begin{array}{l}\text { Bugert et al., } \\
2003 \text { [21] }\end{array}$ & $\begin{array}{l}\text { McRedmond et al., } \\
2004 \text { [23] }\end{array}$ & $\begin{array}{l}\text { Shim et al., } \\
2004[24]\end{array}$ & $\begin{array}{l}\text { Tenedini et al., } \\
2004 \text { [25] }\end{array}$ \\
\hline Genes studied, $\mathrm{n}^{\mathrm{a}}$ & 12,599 & 22,200 & 9,850 & 12,599 & 12,599 & 22,200 \\
\hline $\mathrm{P} / \mathrm{M}^{2}, \mathrm{n}$ & $1,500-2,147$ & NR & NR & NR & NR & appr. 10,000 \\
\hline $\mathrm{P}, \mathrm{n}$ & NR & appr. 1,668 & appr. 1,526 & 2,928 & NR & $4,637-4,655$ \\
\hline Arrays, $\mathrm{n}$ & 3 & 5 & 6 & $\begin{array}{l}1 \text { in duplicate from } \\
23 \text { pooled donors }\end{array}$ & 3 & $\begin{array}{l}4 \text { pooled } \\
\text { (6 samples/array) }\end{array}$ \\
\hline Cells studied & platelets & platelets & platelets & platelets & megakaryocytes & megakaryocytes \\
\hline Cellular source & apheresis & apheresis & concentrates & blood $(50 \mathrm{ml})$ & $\begin{array}{l}\text { CD34+ ex vivo } \\
\text { expandeded }\end{array}$ & CD34+ ex vivo expanded \\
\hline
\end{tabular}

$\mathrm{M}=$ Marginal, $\mathrm{NR}$ = not reported, $\mathrm{P}=$ present, appr. = approximately.

${ }^{a}$ Number of probes (genes) represented on individual microarray slides.

reflects the steady-state mRNA level of the cellular transcriptome $[11,12]$ (www.sagenet.org). With relatively deep sampling (> 50,000 tags), genes expressed at low levels $(<0.01 \%$ of total mRNA) can be readily identified. Two limitations of the current SAGE technology are the relatively short (14 bp) and variable tag lengths caused by the tagging enzyme BsmFI not always cleaving a fixed distance 3 ' into the covalently attached cDNA, and the large amount of redundant DNA sequencing needed for a comprehensive analysis of low-abundant mRNA transcripts [11]. Modifications to the original protocols have been devised for i) generation of longer tags as a means of providing more definitive tag-to-gene identification, ii) efficient identification of low-abundant transcripts using subtractive SAGE techniques, and iii) amplification techniques to circumvent small mRNA starting material [17-19].

\section{Quantitative Reverse Transcription PCR}

Although quantitative reverse transcription PCR (Q-PCR) can be used to monitor expression levels of only a limited subset of transcripts and therefore cannot be applied for wholegenome mRNA profiling, it represents an invaluable tool for the validation of mRNA profiling findings. Q-PCR techniques have also been successfully used to characterize inherited platelet disorders (such as Glanzmann's thrombasthenia and Bernard-Soulier syndrome) and to identify platelet-specific alloantigenes $[9,20]$.

\section{Uncovering the Platelet Transcriptome}

\section{Microarray}

The limited yield of RNA means that potential interference by contaminating leukocyte-derived RNA may bias transcript profiling approaches. Despite this technical concern, a limited number of published microarray studies using megakaryocyteor platelet-derived mRNAs have been described, with generally concordant agreements on transcript quantitation and gene expression patterns (table 1). Not surprisingly, platelets have less transcripts than those found in nucleated cells, ranging from 1,600 to 3,000 mRNAs [21-23]. In particular, platelets express much less transcripts than leukocytes [24, 25] The small number of platelet-expressed transcripts represents the lack of ongoing transcription in the anucleate platelet. The quantitative differences between studies presumably reflect, in part, the methods of isolation.

Several well-characterized platelet transcripts are amongst the most abundant genes identified in the platelet transcriptome (i.e. platelet factor (PF) 4, glycoprotein $1 \mathrm{~b} \beta$,), while numerous transcripts encoding proteins involved in cytoskeletal organization (actin, thymosin $\beta 4$, cofilin) are also readily identified [26] (table 2). A large percentage of genes with miscellaneous $(25 \%)$ or unknown (32\%) function as annotated by Affymetrix and RefSeq databases are also evident [27]. Thus, nearly one half of platelet genes and gene products presumably have important but poorly characterized functions in platelet and/or megakaryocyte biology. The mRNAs encoding the actin-related machinery are overrepresented in these analyses [22] - not unexpected, given prior estimates that $20-30 \%$ of the total platelet proteome is comprised of actin or actin-related proteins, such as mysosin and talin [28]. In unstimulated platelets, $30-40 \%$ of actin is polymerized as Factin, while the balance of G-actin monomers are polymerization-inhibited by sequestering proteins, such as profilin and thymosin $\beta 4$ [29]. The high thymosin $\beta 4$ transcript expression not only correlates with its known abundance in platelets, but supports the importance of actin inhibitory proteins in maintaining the non-stimulated state of circulating platelets. Genes involved in the immune response (chemokines, growth factors and human leukocyte antigen (HLA) proteins) are also evident, consistent with the role of platelets in inflammation and immunity [21]. Finally, unexpected transcripts encoding ery- 
Table 2. Most highly expressed platelet transcripts $(n=50)$

\begin{tabular}{ll}
\hline Platelet transcript $^{\mathrm{a}}$ & $\begin{array}{l}\text { Gene } \\
\text { symbol }\end{array}$ \\
\end{tabular}

Platelet factor 4 (chemokine (C-X-C motif) ligand 4 PF4

H3 histone, family $3 \mathrm{~A}$

Rho guanine nucleotide exchange factor (GEF) 10

$\beta$-Actin mRNA

H3 histone, family 3B

ß2-microglobulin

Neurogranin (protein kinase C substrate)

Pro-platelet basic protein (chemokine (C-X-C motif) ligand 7

Guanine nucleotide-binding protein $G(s), \gamma$-subunit

Thymosin $\beta 4$

Ferritin, light polypeptide

Ferritin, heavy polypeptide 1

Glutathione peroxidase 1

Vinculin

Major histocompatibility complex, class I, B

Glycoprotein $\mathrm{Ib} \beta$

Major histocompatibility complex, class IC

Nuclear receptor coactivator 4

Ornithine decarboxylase antizyme 1

Protein tyrosine phosphatase, receptor-type $\mathrm{O}$

Cofilin 1 (non-muscle)

Chemokine (C-C motif) ligand 5

Transgelin 2

Coagulation factor XIII, A1 polypeptide

Ribosomal protein L41

SH3 domain binding glutamic acid-rich protein like 3

Clusterin (complement lysis inhibitor)

Nerve growth factor receptor-associated protein 1

Major histocompatibility complex, class I, E

Major histocompatibility complex, class I, A

Tumor protein, translationally-controlled 1

Regulator of G-protein signaling 10

SPARC/osteonectin mRNA

Homo sapiens nuclear protein SDK3 mRNA

Monocyte to macrophage differentiation-associated

Hemoglobin $\beta$-gene

MutL homolog 3 (Escherichia coli)

Ubiquitin C

Chromosome 21 open reading frame 7

Ubiquitin B

CD99 antigen

Spermidine/spermine N1-acetyltransferase

Glyceraldehyde-3-phosphate dehydrogenase

Progesterone receptor membrane component 1

Guanine nucleotide binding protein ( $\mathrm{G}$ protein), gamma 11

Myosin, light polypeptide 6 , smooth muscle and non-muscle

Nucleosome assembly protein 1-like

Integral membrane protein $2 \mathrm{~B}$

Hemoglobin, $\alpha_{1}$-gene

Actin related protein 2/3 complex, subunit 1B

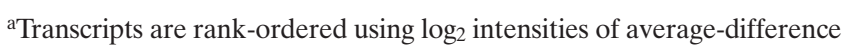
values from 5 normal donors normalized across individual arrays; data and methods updated from $[22,45]$.

PTPRO

CFL1

CCL5

TAGLN2

F13A1

RPL41

SH3BGRL3

CLU

NGFRAP1

HLA-E

HLA-A

TPT1

RGS10

SPARC

PNN

MMD

HBB

MLH3

UBC

C21orf7

UBB

CD99

SAT

GAPD

PGRMC1

GNG11

MYL6

NAP1L1

ITM2B

HBA1

ARPC1B throid genes (i.e. globin, ferritin) have been consistently identified in reported platelet microarray studies. While this may suggest reticulocyte contamination during platelet isolation, residual expression from precursor cells cannot be excluded. Similarly, histone transcripts (notably histone H2A, but also H3.3, H2B.1 and H2A.2) have been observed in transcriptome analysis of highly purified platelets, the significance of which remains unestablished [22].

As a means of better dissecting the molecular anatomy of the platelet, expressed genes grouped on the basis of assigned gene annotations have been used to provide a panoramic definition of the platelet transcriptome. Of the genes that could be catalogued within assigned clusters, those involved in metabolism (11\%) and receptor/signaling (11\%) represented the largest groups. Also evident in these analyses is the relatively large percentage of genes involved in functions unrelated to these key groups (i.e. miscellaneous, $25 \%$ ), and the overrepresentation of genes with unknown function $(32 \%)$ as annotated by Affymetrix and RefSeq databases [30]. These results identify a vast array (nearly one half) of platelet genes and gene products that presumably have important but poorly characterized functions in platelet and/or megakaryocyte biology.

\section{Platelet $S A G E$}

In addition to microarray analysis, limited platelet SAGE has been completed, initial studies cataloguing a total of 2,033 tags [22]. Interestingly, 1,800 tags (89\%) corresponded to mitochondrial-derived genes. The unusually high preponderance of mitochondrial-derived genes is consistent with the known enrichment of these genomes in human platelets [31], and presumably reflects persistent transcription from the mitochondrial genome in the absence of nuclear-derived transcripts. In addition, preliminary observations indicate that nuclear-encoded mitochondrial transcripts are also highly expressed in platelets, suggesting that preservation of mitochondrial functions is crucial for platelet function [32]. The mitochondrial genome is a compact, approximately $16.6 \mathrm{~kb}$ sequence encoding 13 genes and 2 ribosomal RNAs. The overall distribution of platelet-derived mitochondrial SAGE tags is quite similar to that found in muscle [33]. Like muscle, platelets are metabolically adapted to rapidly expend large amounts of energy required for aggregation, granule release and clot retraction. Platelet mitochondria represent the primary source of adenosine triphosphate, and mitochondria are also responsible for most of the toxic reactive oxygen species generated as byproducts of oxidative phosphorylation. The mitochondrial DNA (mtDNA) encodes polypeptides found within 4 of the 5 multifunctional complexes that regulate oxidative phosphorylation within the platelet mitochondria [34]. Whether the continued generation of these polypeptides has a role in platelet energy metabolism and/or the apoptotic mechanisms regulating platelet survival, remains speculative, although not incon- 
Table 3. Platelet and leukocyte RNA yields from variable blood volumes

\begin{tabular}{llllll}
\hline Blood, $\mathrm{ml}$ & \multicolumn{2}{c}{ Platelets } & & & WBC \\
\cline { 6 - 6 } \cline { 5 - 6 } & number & RNA, $\mu \mathrm{g}$ & & number & RNA, $\mu \mathrm{g}$ \\
\hline 1 & $3 \times 10^{8}$ & $0.05-0.01$ & & $5 \times 10^{6}$ & $10-25$ \\
10 & $3 \times 10^{9}$ & $0.5-1$ & & $5 \times 10^{7}$ & $100-250$ \\
100 & $3 \times 10^{10}$ & $5-10$ & & $5 \times 10^{8}$ & $1,000-2,500$ \\
1,000 & $3 \times 10^{11}$ & $50-100$ & & $5 \times 10^{9}$ & $10,000-25,000$ \\
\hline
\end{tabular}

sistent with prior evidence that platelets retain a fully functional translational apparatus [7].

Given the small number of non-mitochondrail SAGE tags available for analysis $(\mathrm{n}=233)$, limited conclusions can be drawn using traditional (non-subtraction) platelet SAGE libraries as presented here. Overall, a total of 126 unique tags have been identified, the majority of which (94) were represented only once. Of the genes with unique tags identified more than once, there was excellent concordance with microarray expression analysis, with nearly all of the SAGE tags corresponding to platelet top 75 microarray transcripts. The PF 4 variant represented a single aberration since this was rank-ordered approximately 350 by microarray, although its SAGE tag frequency was identical to that of the predominant PF4 transcript. Furthermore, a preponderance of the total unique tags was not represented on the microarray chip, thus highlighting the utility of two complimentary systems - open and closed gene profiling approaches.

\section{Overcoming Technical Limitations of Platelet Gene Profiling}

To date, microarray analyses are not standardized, with considerable inter-laboratory variability related to fundamental issues pertaining to platform type (i.e. spotted cDNA vs. oligonucleotide array), RNA extraction and labeling techniques, hybridization conditions and software algorithms for analysis of large datasets. Such issues hinder the exchange of microarray data among various investigators and create considerable challenges to the scientific community in terms of test sensitivity, specificity, reproducibility, reliability and accuracy. The issue of platform reproducibility and quality control may be addressed by the expanded use of commercially available slides (with built-in controls), although the high cost of individual slides creates a barrier for the extensive profiling required to define 'normal'. Thus, even for a microarray with $99 \%$ accuracy $(\mathrm{p}<0.01)$, readouts of 10,000 data points would result in 100 false-positive signals by chance alone. Guidelines for experimental design, data reporting and analysis of microarray experiments have been set forth by the scientific community (www.mged.org), while regulatory issues pertaining to diagnostic testing using microarrays have been outlined [35]. In addition, reliable and reproducible transcript profiling imposes high standard on the purity of platelets and requires excessive purification and leukodepletion. Coupled with exceptionally small RNA content in platelets, this limits widescale studies of platelet transcriptome in patients. Table 3 outlines the relative yield of platelet- and leukocyte-derived RNAs from various starting blood volumes, based on prior determinations of cellular RNA content [36]. Microarray experiments typically require an absolute minimum of $5 \mu \mathrm{g}$ of total cellular RNA, although with appropriate controls and reproducibility issues, $20-100 \mu \mathrm{g}$ requirements are more typical. As evident, nearly 11 of blood would be required to ensure the availability of sufficient RNA for reliable studies, an amount that would be overwhelmed by leukocyte-derived RNA. Nonetheless, current methodologies entailing approximately 3-log leukodepletion result in sufficiently pure platelet mRNA for reliable interpretation of these experiments [22]. Given the importance of leukocyte depletion in transfusion medicine, it is likely that more efficient and stringent approaches will be developed in the foreseeable future. Finally, while sophisticated technologies, such as laser microdissection, have been described for removal of leukocytes, the general applicability of such methodology remains to be determined [3].

Several groups have devised modified protocols which require significantly less starting material, typically less than $100 \mathrm{ng}$ of mRNA. Most of these procedures incorporate the known ability of Moloney murine leukemia virus reverse transcriptase to efficiently add several unencoded $\mathrm{dC}$ residues when it reaches the 5' end of the RNA. When cDNA synthesis is primed by oligo(dT) in the presence of a second oligonucleotide with a short stretch of dG residues at its $3^{\prime}$ end, this second oligo anneals to the polyC extensions and provides a template for further cDNA extension by the reverse transcriptase [37]. The enzyme is therefore able to switch templates and incorporates the complement to the template switching (TS) oligonucleotide. In principle, every first-strand cDNA will now have a common sequence at its $3^{\prime}$ end which is complementary to the TS sequence. Thus, a TS oligonucleotide can be used in combination with a biotinylated oligo(dT) primer to PCR-amplify the cDNA, allowing much smaller amounts of starting mRNA to be utilized. Comparable adaptations have been used to generate high-quality cDNA for microarray analysis starting from as little as $1 \mathrm{pg}$ of total starting RNA isolated from 9 human oocytes [38]. When combined with methods for high-fidelity in vitro transcript amplification using T7 RNA polymerase, it is likely that platelet analysis from small blood volumes will be feasible. Recently, a thorough study of the feasibility of the analysis of platelet transcriptome from a single donor using RNA amplification technique has been reported [39]. The aim of this study was to establish a protocol that makes analysis of platelet transcriptome applicable to a single patient with suspected platelet disorder. Platelets were depleted from leukocytes by centrifugation and filtration, and total RNA was amplified using a commercially available PCR-based RNA amplification kit (switching mechanism at the 5' end of RNA templates, SMART, BD Biosciences Clontech, Mountain 
Fig. 3. Pathways of androgen formation and differential expression of 17ß-hydroxysteroid dehydrogenases type 3 (HSD17B3) and type 12 (HSD17B12) in normal and ET platelets. Changes in gene expression were calculated from microarray data. Function of HSD17B12 in the steroid metabolism pathway remains unknown.

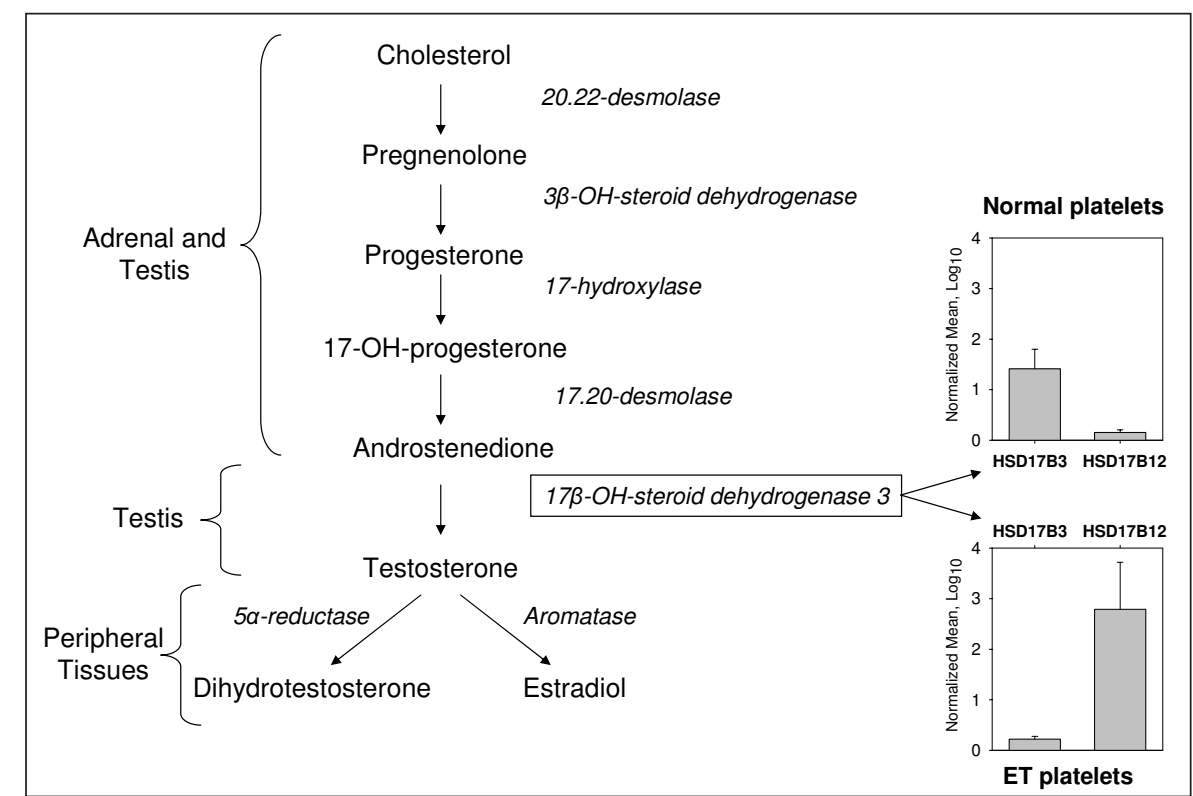

View, CA, USA). Reliability and precision of RNA amplification was evaluated by Q-PCR using selected platelet-expressed transcripts. Microarray analysis was performed using a glass chip containing probes to 9,850 genes (MWG-Biotech AG). Microgram quantities of cDNAs were produced from as little as $50 \mathrm{ng}$ of total platelet RNA or $40 \mathrm{ml}$ of a whole blood. Amplification of all monitored transcripts was exponential to the cycle number 16 . Gene profiling gave similar results for 9,815 of the 9,850 genes, with 1,576 positive and 8,239 negative. Interestingly, only 8 transcripts failed to be amplified, and amplification efficiency was slightly higher for low-abundant transcripts. In addition, day-to-day variability in the expression of selected transcripts in 3 healthy individuals has been addressed and found to be minor. The authors concluded that the SMART amplification protocol does not cause significant distortion of the gene expression profile and can potentially be applied for routine studies of the platelet transcriptome for individual patients.

\section{Application of Platelet Transcriptomics to Hematological Diseases}

\section{Essential Thrombocythemia as a Paradigm}

The utility of gene expression profiling for the molecular classification of human cancer is well-documented, although its applicability to poorly-understood myeloproliferative disorders, such as essential thrombocythemia (ET) remains unestablished. ET represents a myeloproliferative disorder subtype, characterized by increased proliferation of megakaryocytes, elevated numbers of circulating platelets and considerable thrombohemorrhagic events, not infrequently neurological [40]. The molecular basis of ET remains unestablished, and his- torically it has been considered a clonal disorder [41], although recent discovery of an acquired mutation in the Janus kinase 2 (JAK2) gene may shed a light on the molecular mechanism of this disease [42-44]. Recently, a microarray approach was used to gain further insight into the specific changes associated with the ET phenotype and to identify genes that could discriminate between morphologically indistinguishable ET and normal platelets [45]. Initial analysis of the genetic profiles of highly purified apheresis platelets isolated from $6 \mathrm{ET}$ patients ( $4 \mathrm{fe}-$ males, 2 males) and 5 normal, healthy controls demonstrated distinctly different molecular signatures. ET platelets collectively demonstrated higher numbers of expressed transcripts compared to normal controls, but considerably less than the transcript numbers generally found in nucleated cells [22]. Of the genes classified as marginal or present in a minimum of 4 microarrays, ET patient samples expressed an average of 3,562 transcripts compared to 1,668 in normal controls. Normal or ET platelets have genetic profiles distinct from leukocytes, and notable differences between normal and ET platelets were clearly evident. Initial one-way analysis of variance identified 170 differentially expressed genes, the majority of which (141) were up-regulated in ET platelets. Only 29 genes were downregulated compared to normal platelets. Functional cluster analysis of this limited set of differentially expressed genes demonstrated that genes involved in adhesion and catalytic activity represented the largest subgroups (38 and 32\%, respectively), although a sizable number of genes $(35 \%)$ remained unclassified.

It was found that normal human blood platelets express HSD17B3 enzyme (type 3 17 $\beta$-hydroxysteroid dehydrogenase), previously described as testis-specific. This enzyme belongs to a large family of 17BHSDs and is known to catalyze the penultimate step in testosterone biosynthesis (fig. 3). Molecular defects of the HSD17B3 gene are causally implicated in 
male pseudohermaphroditism [46]. In addition to HSD17B3, transcripts for two more members of this family were found in human platelets - HSD17B11 and HSD17B12. While the $H S D 17 B 11$ mean, normalized signals between the normal and diseased cohorts were low-level and not statistically different, there was a striking change in the pattern of $H S D 17 B 3$ and HSD17B12 expression between ET and normal platelets. Absence of HSD17B3 transcript expression was evident in all 6 ET patients, changes that occurred concomitantly with elevated transcript levels of $H S D 17 B 12$ in the same patient subgroup. In contrast, expression of $H S D 17 B 3$ in normal platelets was accompanied by negligible to low-level HSD17B12 expression. Several independent methods were used to validate and extend studies of 17 $\beta$-hydroxysteroid dehydrogenases in normal and ET platelets. Initial findings were confirmed both at the mRNA level by Q-PCR and at the protein level by the analyses of functional activity of HSD17B3. Recent studies demonstrated that another sex hormone, estradiol, is produced in megakaryocytes [47]. Moreover, proplatelet formation of megakaryocytes was triggered by autocrine-synthesized estradiol. It was clearly demonstrated that the inhibition of another key enzyme for steroid hormone biosynthesis, $3 \beta$-hydroxysteroid dehydrogenase $(3 \beta-\mathrm{OH}$-steriod dehydrogenase, fig. 3), blocks proplatelet formation. In addition, estrogen receptor antagonists inhibit platelet production in vivo. Taken together, these data suggest that sex hormones and enzymes involved in steroid metabolism may play an important role in megakaryocyte maturation and proplatelet formation. In summary, transcript profiling demonstrated noticeable difference between the spectrum of mRNAs expressed in normal and ET platelets, thus contributing to the generation of the molecular signature of ET. Moreover, these data establish a novel link between platelet function and hormone steroidogenic pathways that may be causally implicated in platelet-mediated thrombotic events and/or platelet production.

\section{Indirect Studies of Platelet Disorders: Gray Platelet Syndrome} and Polycythemia vera

Molecular mechanisms of other platelet disorders, such as gray platelet syndrome (GPS), were also studied by transcript profiling, although these studies were not focused on platelets as a source of RNA. GPS is a rare congenital bleeding disorder of unknown origin, with phenotypic and genetic heterogeneity, characterized by thrombocytopenia, increased platelet size and decreased alpha-granule content [48-50]. In order to investigate mechanisms involved in GPS, the microarray approach was applied [51]. In pursuing the etiology of GPS, fibroblasts were employed as a model system, partly because the myelofibrosis in this subtype of GPS was likely to involve these cells. Normal and GPS fibroblasts were cultured from skin biopsy, and the differential expression of 4,900 unique genes was evaluated by microarray techniques. Differ- entially expressed genes were clustered according to the change in their expression, and genes within each cluster were tested for functional similarities. Significant up-regulation of expression of the cytoskeleton proteins fibronectin 1, thrombospondins 1 and 2 and collagen VI $\alpha$ was demonstrated. Overexpression of fibronectin and thrombospondin 1 was independently confirmed at the RNA level by Northern blotting. In addition, up-regulation of expression of fibronectin was confirmed at the protein level by immunostaining. These results clearly demonstrate the feasibility of a transcriptome approach to identify gene candidates involved in GPS and suggest that cytoskeleton proteins may play an important role in the molecular mechanisms of this rare disorder.

Polycythemia vera (PV) is a myeloproliferative disorder of unknown molecular pathogenesis. It is characterized by increased proliferation of all 3 myeloid lineages with subsequent overproduction of mature red cells, granulocytes and platelets [52]. Initially, microarray analysis was employed to identify genes which are differentially expressed in normal and PV granulocytes [53]. Evaluation of expression levels of 6,000 genes revealed that 147 genes were up-regulated in the majority of PV patients compared to normal. 11 of these genes were elevated in all 11 patients studied. In addition, elevated expression of several protease inhibitors with affinity for proteases involved in apoptosis and a number of antiapoptotic factors has been documented.

Another study focused on the differential diagnosis between PV and secondary erythrocytosis (SE) [54]. Granulocytes were purified from peripheral blood of $40 \mathrm{PV}$ patients, $12 \mathrm{SE}$ patients and 50 healthy volunteers. RNA was isolated and hybridized to the customized cDNA microarray chip, containing probes for 7,497 genes. Two independent sets of data were obtained. First, a set of 64 genes was determined, which correctly distinguish RV from SE, thus representing a valuable diagnostic tool. Second, 644 genes were identified as differentially expressed in PV patients compared to normal (253 up-regulated, and 341 down-regulated in PV, $\mathrm{p}<0.01)$. Many genes which are up-regulated in PV are controlled by Spl-like transcription factors. One of them, transcription factor NF-E2 was overexpressed 2-40-fold in PV patients compared to normal. In addition, overexpression of this transcription factor was documented in erythroid and myeloid precursors and in megakaryocytes of PV patients. These data establish the feasibility of the differential diagnosis of myeloproliferative disorders based on the molecular signature of the diseases and suggest that transcription factor NF-E2 may be involved in the molecular etiology of PV.

\section{Conclusion}

Taken together, platelet mRNA profiling studies have defined the basic platelet transcriptome. It is clear that platelets have a distinct and reproducible transcript profile. Moreover, tran- 
script profiles of normal and diseased platelets are significantly different, as was demonstrated for ET and PV. Transcript profiling not only defines the molecular signature of platelets in normal and diseased states, but also can be used for identification of novel proteins previously unknown to be expressed in platelets. To date, genetic profiling techniques have focused on well-defined (but rare) congenital platelet disorders, although their applicability to more common disorders affecting platelets (i.e. cardiovascular and cerebrovascular diseases) remains unestablished.

Recent advances in platelet proteomic studies give further insight into mechanisms of platelet function and permit identification of novel proteins at an unprecedented scale [55-60]. The discovery of pre-mRNA splicing in platelets [10] opens new perspectives in studying the complexity of transcriptomeproteome correlations. Platelet-restricted signal-dependent splicing contributes to previously unrecognized complexity regulating the platelet proteome, although its physiological consequences remain unestablished. Whether alternative splicing occurs in platelets in response to various exogenous factors or diseases, is also unknown, although this issue can be partially addressed by the next generation of microarray chips which should allow the detection of alternatively spliced transcripts. Integrated platelet transcriptomics and proteomics will represent a powerful tool to study complex processes underlying platelet regulatory functions and identify potential new therapeutic targets in platelets.

\section{Acknowledgements}

This work was supported by grants HL49141, HL53665, HL76457, Department of Defense \#MPO48005, a Targeted Research Award from Stony Brook University, and NIH Center grant MO1 10710-5 to the University Hospital General Clinical Research Center.

\section{References}

1 Stenberg PE, Hill RL: Platelets and megakaryocytes; in Lee G, Foerster J, Lukens J, Paraskevas F, Greer JP, Rodgers GM (eds): Wintrobe's Clinical Hematology. Philadelphia, Linnincott William and Wilkins, 1999.

2 Newman P, Gorski J, White G, Gidwitz S, Cretney C, Aster R: Enzymatic amplification of plateletspecific messenger RNA using the polymerase chain reaction. J Clin Invest 1988;82:739-743.

3 Fink L, Holschermann H, Kwapiszewska G, Muyal JP, Lengemann B, Bohle RM, Santoso S: Characterization of platelet-specific mRNA by real-time PCR after laser-assisted microdissection. Thromb Haemost 2003;90:749-756.

$\checkmark 4$ Rinder H, Schuster J, Rinder C, Wang C, Schweidler H, Smith B: Correlation of thrombosis with increased platelet turnover in thrombocytosis. Blood 1998;91:1288-1294.

5 Kieffer N, Guichard J, Farcet J, Vainchenker W, Breton-Gorius J: Biosynthesis of major platelet proteins in human blood platelets. Eur J Biochem 1987;164:189-195.

6 Weyrich AS, Zimmerman GA: Platelets: signaling cells in the immune continuum. Trends Immunol 2004;25:489-495.

7 Weyrich A, Dixon D, Pabla R, Elstad M, McIntyre T, Prescott S, Zimmerman G: Signal-dependent translation of a regulatory protein, $\mathrm{Bcl}-2$, in activated human platelets. Proc Nat Acad Sci U S A 1998; 95:5556-5561.

8 Bahou W: Genetic disorders in platelets; in Kumar D (ed): Genomics and Clinical Medicine. Oxford, Oxford University Press, 2006 (in press).

9 Nurden A, Nurden P: Inherited disorders of platelet function; in Michelson AD (ed): Platelets. London, Academic Press, 2002.

10 Denis MM, Tolley ND, Bunting M, Schwertz H, Jiang H, Lindemann S, Yost CC, Rubner FJ, Albertine KH, Swoboda KJ, Fratto CM, Tolley E, Kraiss LW, McIntyre TM, Zimmerman GA, Weyrich AS: Escaping the nuclear confines: signal-dependent pre-mRNA splicing in anucleate platelets. Cell 2005;122:379-391.

11 Velculescu V, Zhang L, Vogelstein B, Kinzler K: Serial analysis of gene expression. Science 1995;270: 484-487.
12 Zhang L, Zhou W, Velculescu V, Kern S, Hruban R, Hamilton S, Vogelstein B, Kinzler K: Gene expression profiles in normal and cancer cells. Science 1997;276:1268-1272.

13 Butte A: The use and analysis of microarray data. Nat Rev Drug Discov 2002:1:951-960.

14 Golub TR, Slonim DK, Tamayo P, Huard C, Gaasenbeek M, Mesirov JP, Coller H, Loh ML, Downing JR, Caligiuri MA, Bloomfield CD, Lander ES: Molecular classification of cancer: class discovery and class prediction by gene expression monitoring. Science 1999;286:531-537.

15 Alizadeh AA, Eisen MB, Davis RE, Ma C, Lossos IS, Rosenwald A, Boldrick JC, Sabet H, Tran T, Yu X, Powell JI, Yang L, Marti GE, Moore T, Hudson J Jr, Lu L, Lewis DB, Tibshirani R, Sherlock G, Chan WC, Greiner TC, Weisenburger DD, Armitage JO, Warnke R, Levy R, Wilson W, Grever MR, Byrd JC, Botstein D, Brown PO, Staudt LM: Distinct types of diffuse large B-cell lymphoma identified by gene expression profiling. Nature 2000;403:503-511.

16 Bertucci F, Nasser V, Granjeaud S, Eisinger F, Adelaide J, Tagett R, Loriod B, Giaconia A, Benziane A, Devilard E, Jacquemier J, Viens P, Nguyen C, Birnbaum D, Houlgatte R: Gene expression profiles of poor-prognosis primary breast cancer correlate with survival. Hum Mol Genet 2002;11: 863-872.

17 Dunn JJ, McCorkle SR, Praissman LA, Hind G, Van Der Lelie D, Bahou WF, Gnatenko DV, Krause MK: Genomic signature tags (GSTs): a system for profiling genomic DNA. Genome Res 2002;12:1756-1765.

18 Wang E, Miller L, Ohnmacht G, Liu E, Marincola F: High-fidelity mRNA amplification for gene profiling. Nat Biotechnol 2000;18:157-459.

19 Peters DG, Kassam AB, Yonas H, O'Hare EH, Ferrell RE, Brufsky AM: Comprehensive transcript analysis in small quantities of mRNA by SAGELite. Nucleic Acids Res 1999;27:e39.

20 Metcalfe P, Watkins NA, Ouwehand WH, Kaplan C, Newman P, Kekomaki R, De Haas M, Aster R, Shibata Y, Smith J, Kiefel V, Santoso S: Nomenclature of human platelet antigens. Vox Sang 2003;85: 240-245.
21 Bugert P, Dugrillon A, Gunaydin A, Eichler H, Kluter H: Messenger RNA profiling of human platelets by microarray hybridization. Thromb Haemost 2003;90:738-748.

22 Gnatenko DV, Dunn JJ, McCorkle SR, Weissmann D, Perrotta PL, Bahou WF: Transcript profiling of human platelets using microarray and serial analysis of gene expression. Blood 2003;101:2285-2293.

23 McRedmond JP, Park SD, Reilly DF, Coppinger JA, Maguire PB, Shields DC, Fitzgerald DJ: Integration of proteomics and genomics in platelets: a profile of platelet proteins and platelet-specific genes. Mol Cell Proteomics 2004;3:133-144.

24 Shim MH, Hoover A, Blake N, Drachman JG, Reems JA: Gene expression profile of primary human CD34+CD38lo cells differentiating along the megakaryocyte lineage. Exp Hematol 2004;32: 638-648.

25 Tenedini E, Fagioli ME, Vianelli N, Tazzari PL, Ricci F, Tagliafico E, Ricci P, Gugliotta L, Martinelli G, Tura S, Baccarani M, Ferrari S, Catani L: Gene expression profiling of normal and malignant CD34-derived megakaryocytic cells. Blood 2004; 104:3126-3135.

26 Bahou WF, Gnatenko DV: Platelet transcriptome: the application of microarray analysis to platelets. Semin Thromb Hemost 2004;30:473-484.

27 Pruitt K, Maglott DR: RefSeq and LocusLink: NCBI gene-centered resources. Nucleic Acids Res 2001;29:137-140.

28 Fox JE, Boyles JK, Berndt MC, Steffen PK, Anderson LK: Identification of a membrane skeleton in platelets. J Cell Biol 1988;106:1525-1538.

29 Safer D, Elzinga M, Nachmias VT: Thymosin beta 4 and $\mathrm{Fx}$, an actin-sequestering peptide, are indistinguishable. J Biol Chem 1991;266:4029-4032.

30 Kroll TC, Wolfl S: Ranking: a closer look on globalisation methods for normalisation of gene expression arrays. Nucleic Acids Res 2002;30:e50.

31 Wallace DC: Mouse models for mitochondrial disease. Am J Med Genet 2001;106:71-93.

32 Macaulay IC, Carr P, Farrugia R, Watkins NA: Analysing the platelet transcriptome. Vox Sang 2004;87(suppl 2):42-46.

33 Welle S, Bhatt K, Thornton C: Inventory of highabundance mRNAs in skeletal muscle of normal men. Genome Res 1999;9:506-513. 
34 Raha S, Robinson BH: Mitochondria, oxygen free radicals, and apoptosis. Am J Med Genet 2001;106: 62-70.

35 Petricoin EF 3rd, Hackett JL, Lesko LJ, Puri RK, Gutman SI, Chumakov K, Woodcock J, Feigal DW Jr, Zoon KC, Sistare FD: Medical applications of microarray technologies: a regulatory science perspective. Nat Genet 2002;32(suppl):474-479.

\$36 Wicki AN, Walz A, Gerber-Huber SN, Wenger RH, Vornhagen R, Clemetson KJ: Isolation and characterization of human blood platelet mRNA and construction of a cDNA library in lambda gt11. Confirmation of the platelet derivation by identification of GPIb coding mRNA and cloning of a GPIb coding cDNA insert. Thromb Haemost 1989;61:448- 453.

37 Zhu Y, Machleder E, Chenchik A, Li R, Siebert P: Reverse transcriptase template switching: a SMART approach for full-length cDNA library construction. Biotechniques 2001;30:892-897.

$\checkmark 38$ Neilson L, Andalibi A, Kang D, Coutifaris C, Strauss JF 3rd, Stanton JA, Green DP: Molecular phenotype of the human oocyte by PCR-SAGE. Genomics 2000;63:13-24.

39 Rox JM, Bugert P, Muller J, Schorr A, Hanfland P, Madlener K, Kluter H, Potzsch B: Gene expression analysis in platelets from a single donor: evaluation of a PCR-based amplification technique. Clin Chem 2004;50:2271-2278.

40 Nimer SD: Essential thrombocythemia: another 'heterogeneous disease' better understood? Blood 1999;93:415-416.

- 41 El-Kassar N, Hetet G, Briere J, Grandchanp B: Clonality analysis of hematopoiesis in essential thrombocythemia: advantages of studying T lymphocytes and platelets. Blood 1997;89:128.

42 Baxter EJ, Scott LM, Campbell PJ, East C, Fourouclas N, Swanton S, Vassiliou GS, Bench AJ, Boyd EM, Curtin N, Scott MA, Erber WN, Green AR: Acquired mutation of the tyrosine kinase JAK2 in human myeloproliferative disorders. Lancet 2005;365:1054-1061.
43 James C, Ugo V, Le Couedic JP, Staerk J, Delhommeau F, Lacout C, Garcon L, Raslova H, Berger R, Bennaceur-Griscelli A, Villeval JL, Constantinescu $\mathrm{SN}$, Casadevall N, Vainchenker W: A unique clonal JAK2 mutation leading to constitutive signalling causes polycythaemia vera. Nature 2005;434:11441148.

44 Kralovics R, Passamonti F, Buser AS, Teo SS, Tiedt R, Passweg JR, Tichelli A, Cazzola M, Skoda RC: A gain-of-function mutation of JAK2 in myeloproliferative disorders. N Engl J Med 2005;352:17791790.

45 Gnatenko DV, Cupit LD, Huang EC, Dhundale A, Perrotta PL, Bahou WF: Platelets express steroidogenic 17beta-hydroxysteroid dehydrogenases. Distinct profiles predict the essential thrombocythemic phenotype. Thromb Haemost 2005;94:412-421.

46 Geissler WM, Davis DL, Wu L, Bradshaw KD, Patel S, Mendonca BB, Elliston KO, Wilson JD, Russell DW, Andersson S: Male pseudohermaphroditism caused by mutations of testicular 17 betahydroxysteroid dehydrogenase 3. Nat Genet 1994; 7:34-39.

47 Nagata Y, Yoshikawa J, Hashimoto A, Yamamoto M, Payne AH, Todokoro K: Proplatelet formation of megakaryocytes is triggered by autocrine-synthesized estradiol. Genes Dev 2003;17:2864-2869.

48 Hayward CP, Weiss HJ, Lages B, Finlay M, Hegstad AC, Zheng S, Cowie A, Masse JM, Harrison P, Cramer EM: The storage defects in grey platelet syndrome and alphadelta-storage pool deficiency affect alpha-granule factor $\mathrm{V}$ and multimerin storage without altering their proteolytic processing. $\mathrm{Br}$ J Haematol 2001;113:871-877.

49 Aronson I, Du Toit JM, Jacobs P: Grey platelet syndrome. Lancet 1994;344:1233-1234.

50 Srivastava PC, Powling MJ, Nokes TJ, Patrick AD, Dawes J, Hardisty RM: Grey platelet syndrome: studies on platelet alpha-granules, lysosomes and defective response to thrombin. $\mathrm{Br} \mathrm{J}$ Haemato 1987:65:441-446.
51 Hyman T, Huizing M, Blumberg PM, Falik-Zaccai TC, Anikster Y, Gahl WA: Use of a cDNA microarray to determine molecular mechanisms involved in grey platelet syndrome. Br J Haematol 2003;122:142-149.

52 Adamson JW, Fialkow PJ, Murphy S, Prchal JF, Steinmann L: Polycythemia vera: stem-cell and probable clonal origin of the disease. N Engl J Med 1976;295:913-916.

53 Pellagatti A, Vetrie D, Langford CF, Gama S, Eagleton $\mathrm{H}$, Wainscoat JS, Boultwood J: Gene expression profiling in polycythemia vera using cDNA microarray technology. Cancer Res 2003;63:39403944.

54 Goerttler PS, Kreutz C, Donauer J, Faller D, Maiwald T, Marz E, Rumberger B, Sparna T, SchmittGraff A, Wilpert J, Timmer J, Walz G, Pahl HL: Gene expression profiling in polycythaemia vera: overexpression of transcription factor NF-E2. Br J Haematol 2005;129:138-150.

55 Coppinger JA, Cagney G, Toomey S, Kislinger T, Belton O, McRedmond JP, Cahill DJ, Emili A, Fitzgerald DJ, Maguire PB: Characterization of the proteins released from activated platelets leads to localization of novel platelet proteins in human atherosclerotic lesions. Blood 2004;103:2096-2104.

56 Maguire PB, Foy M, Fitzgerald DJ: Using proteomics to identify potential therapeutic targets in platelets. Biochem Soc Trans 2005;33:409-412.

57 Maguire PB, Moran N, Cagney G, Fitzgerald DJ: Application of proteomics to the study of platelet regulatory mechanisms. Trends Cardiovasc Med 2004;14:207-220.

58 Maguire PB, Fitzgerald DJ: Platelet proteomics. J Thromb Haemost 2003;1:1593-1601.

59 Maguire PB, Wynne KJ, Harney DF, O'Donoghue NM, Stephens G, Fitzgerald DJ: Identification of the phosphotyrosine proteome from thrombin activated platelets. Proteomics 2002;2:642-648.

60 Moebius J, Zahedi RP, Lewandrowski U, Berger C, Walter U, Sickmann A: The human platelet membrane proteome reveals several new potential membrane proteins. Mol Cell Proteomics 2005;4 1754-61. 